\title{
Roles and mechanisms of ginsenoside in cardiovascular diseases: progress and perspectives
}

\author{
Yingying $\operatorname{Sun}^{1}$, Yue Liu $^{1,2^{*}} \&$ Keji Chen ${ }^{1,2}$ \\ ${ }^{1}$ Cardiovascular Diseases Centre, Xiyuan Hospital of China Academy of Chinese Medical Sciences, Beijing 100091, China; \\ ${ }^{2}$ China Heart Institute of Chinese Medicine, China Academy of Chinese Medical Sciences, Beijing 100091, China
}

Received September 8, 2015; accepted November 4, 2015; published online January 20, 2016

\begin{abstract}
Ginseng is among the oldest traditional Chinese medicinal herbs and is widely used in China and Southeast Asia. Over the past 50 years, considerable research has focused on the chemical constituents, pharmacological action, and clinical applications of ginseng. In this review, we examine the current state of research on ginseng, including the main active ingredient ginsenoside, its pharmacological effects on the cardiovascular system, and mechanisms of action. We focus on what is known of the effects of ginseng against atherosclerosis, arrhythmia, myocardial ischemia, and its inhibition of ventricular remodeling, providing a basis for expanding the clinical applications of ginseng.
\end{abstract}

ginseng, ginsenoside, cardiovascular disease, mechanisms

Citation: Sun, Y., Liu, Y., and Chen, K. (2016). Roles and mechanisms of ginsenoside on cardiovascular diseases: progress and perspectives. Sci China Life Sci 59, 292-298. doi: 10.1007/s11427-016-5007-8

\section{INTRODUCTION}

Ginseng (Panax ginseng C.A. Meyer) is a perennial herb originating from the Tertiary period with about 60 million years of history that has survived because of genetic variations incurred during the Quaternary glacial epoch. It is often referred to as a periglacial plant and living fossil, and enjoys a reputation as the King of Herbs. Each part of the ginseng plant-but particularly the root-has high medicinal value and is widely used in Asia. According to Shennong's Herbal Classic, ginseng is one of the popular medicines for nourishing the body and can be taken over a long term without causing harm. Ginseng is sweet, tepid after processing, and non-toxic, and has an anti-aging effect owing to its ability to tonify Qi; this has been described in Zhang Zhongjing's book Treatise on Cold Pathogenic and Miscellaneous Diseases ("Shanghan Za Bing Lun"), Li Shizhen's work Compendium of Materia Medica ("Ben Cao

*Corresponding author (email: liuyueheart@yahoo.com)
Gang $M u$ "), and a variety of books on herbal medicine since the Qing Dynasty. It is also known to reinforce vital energy, fortify the spleen to benefit the lungs, nourish fluids, calm the heart, tranquilize the mind, and so on.

In the last 50 years, there has been considerable research on the active ingredients, pharmacological effects, and clinical applications of ginseng. The academic monograph Chemistry, Biological Activity and Pharmacokinetics of Panax ginseng Meyer (Zhang, 2012) has been updated to version 2 and is widely influential. Ginseng has various physiological effects; it is known to reduce fatigue, improve immunity, slow aging, inhibit cancer metastasis, regulate blood sugar, protect liver and kidney functions, and has nootropic effects, with two-way regulation of the central nervous system (Zhang, 1995; Chu and Zhang, 2009).

Cardiovascular diseases account for a large percentage of disease-related deaths worldwide, and as such, the discovery of novel drugs or compounds among traditional herbal medicines that have cardiovascular protective effects is a focus of intense research (Hao et al., 2015; Yao et al., 
2015). Research on the cardiovascular pharmacology of ginseng has aroused great interest among scholars in recent years. The present review discusses the research carried out over the past decade in China and elsewhere on the main active ingredient of ginseng (i.e., ginsenoside), its pharmacological effects on cardiovascular function, and the underlying mechanisms of action. We specifically focus on the cardiovascular properties of ginseng, including its anti-atherosclerotic, anti-arrhythmic, and anti-myocardial ischemic effects and its inhibitory effects on ventricular remodeling. This evidence can provide a basis for further research on ginseng and expand its clinical applications.

\section{CHEMICAL COMPONENTS OF GINSENG}

More than 300 compounds have been isolated from ginseng. These include ginsenoside, the main active ingredient and one of more than 50 saponin monomers that influence metabolism as well as immune, antioxidant, endocrine, and central nervous systems and are used in the treatment and prevention of cardiovascular diseases; as well as polysaccharides, amino acids, proteins, carbohydrates, vitamins, organic acids, trace elements, and flavonoids.

Ginsenoside is a glycoside formed by removal of a water molecule from the hemiacetal hydroxyl of a sugar molecule and a hydroxyl from non-carbohydrate compounds. Ginsenoside differs from other saponins in terms of the ring structure of sapogenin. Ginsenosides can be classified into oleanolic acid, protopanaxadiol, and protopanaxatriol types based on the parent ring structure (Bai et al., 2014; Kim et al., 2015) (Figure 1 and Table 1).

\section{CARDIOVASCULAR PHARMACOLOGICAL EFFECTS OF GINSENOSIDE AND MECHANISMS OF ACTION}

\section{Anti-atherosclerotic effects and protection of the vascu- lar endothelium}

Coronary heart disease is among the most common diseases and is caused by atherosclerosis (AS)-induced endothelial dysfunction leading to systemic organ disease (An et al.,

Table 1 Classification of ginsenosides

\begin{tabular}{ll}
\hline Subtype & Ginsenoside \\
\hline Protopanaxadiol (PPD) type & $\mathrm{Ra}(1,2,3)$ \\
& $\mathrm{Rb}(1,2,3)$ \\
& $\mathrm{Rc}$ \\
& $\mathrm{Rd}$ \\
$\mathrm{Rg} 3^{+}$ \\
$\mathrm{Rh} 2^{+}$ \\
F2 \\
Oleanolic acid type & $\mathrm{Compound} \mathrm{K}$ \\
& $\mathrm{Ro}$ \\
Protopanaxatriol (PPT) type & $\mathrm{Rh} 3$ \\
& $\mathrm{Ri}$ \\
& $\mathrm{Rg} 1$ \\
& $\mathrm{Rg} 2$ \\
$\mathrm{Re}$ \\
$\mathrm{Rf}$ \\
$\mathrm{Rh} 1$ \\
$\mathrm{~F} 1$ \\
\hline
\end{tabular}

A
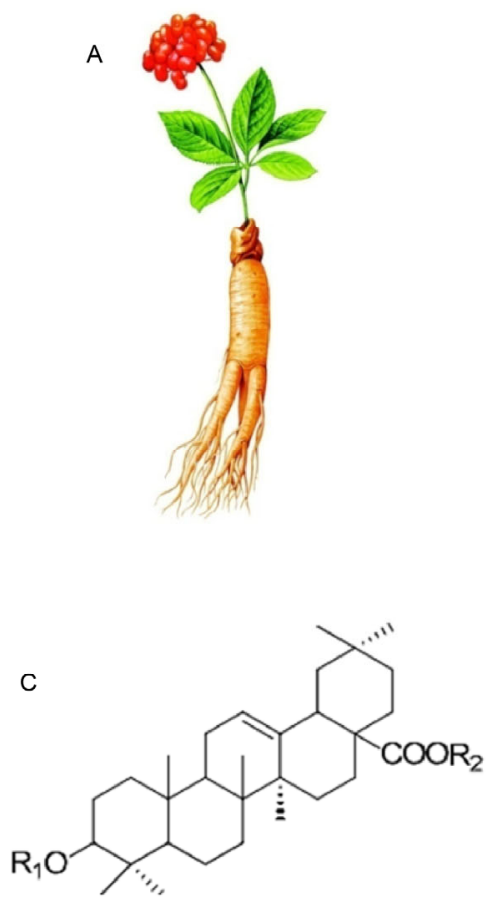

B

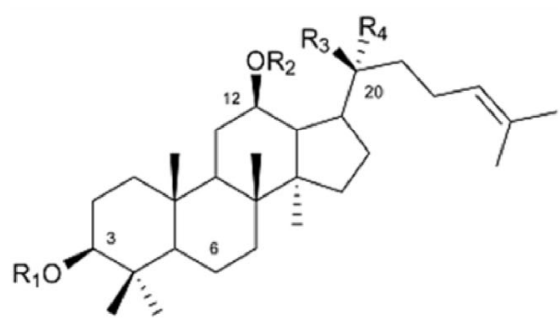

Figure 1 Panax ginseng C.A. Meyer plant and chemical structures of ginsenoside subtypes. A, Illustration of Panax ginseng C.A. Meyer. B-D, Chemical structures of protopanaxadiol-type (B), oleanolic acid-type (C), and protopanaxatriol-type (D). 
2014; Zhang and Dong, 2014), which is associated with a high rate of morbidity and mortality. Risk factors for coronary AS include dyslipidemia, hyperglycemia, hypertension, and platelet aggregation and activation.

Oxidized low-density lipoprotein (oxLDL) inhibits lactate dehydrogenase (LDH) activity, decreases endothelial nitric oxide synthase (NOS) expression, and modulates tissue-type plasminogen activator and plasminogen activator inhibitor 1 (PAI-1) activities. Studies on human umbilical vein endothelial cells (HUVECs) pretreated for $24 \mathrm{~h}$ with a high dose of ginsenoside $\mathrm{Rb} 1\left(10 \mathrm{mg} \mathrm{mL}^{-1}\right)$ have reported an inhibition of oxLDL and consequent protection of endothelial cells (He et al., 2007). Hyperlipidemic rats fed ginsenoside Rh2 (200 mg kg-1 $\mathrm{d}^{-1}$ ) for 11 weeks showed reduced serum LDL-C and total cholesterol (TC) levels and increased serum NO and superoxide dismutase activities. $\mathrm{Rh} 2$ also decreased malondialdehyde levels, reduced lipid peroxidation, enhanced oxygen free radical scavenging, and stabilized cell membranes, thereby protecting endothelial cells via these anti-AS effects (Kong et al., 2010). Similarly, hyperlipidemic rats treated with ginsenoside $\mathrm{Rb}$ (50-200 mg kg ${ }^{-1} \mathrm{~d}^{-1}$ ) for $12 \mathrm{~d}$ showed decreased serum TC, triglyceride (TG), and LDL-C levels and increased HDL-C level, suggesting that $\mathrm{Rb}$ enhanced cholesterol transport from peripheral tissues to the liver, which in turn reduced cholesterol accumulation and prevented endothelial cell damage and AS (Zhang et al., 2004). In a rat carotid artery injury model, ginsenoside $\mathrm{Rg} 1$ improved tissue damage caused by aortic injury and neointimal thickening, suggesting that it can inhibit neointimal hyperplasia, possibly by reducing oxidative stress and stimulating NOS expression and NO production (Gao et al., 2012). Ginsenosides have also been shown to inhibit nuclear factor $\kappa \mathrm{B}$ signaling $(\mathrm{Ru}-$ an et al., 2004) by suppressing lipopolysaccharide-induced PAI-1 expression, promoting fibrinolysis, and preventing thrombosis in HUVECs. In a spontaneously hypertensive rat model, Rb1 reduced blood pressure at high $\left(60 \mathrm{mg} \mathrm{kg}^{-1}\right)$ and low $\left(30 \mathrm{mg} \mathrm{kg}^{-1}\right)$ doses over a 12-week period, possibly via regulation of the balance between helper T17 and regulatory $\mathrm{T}$ cells (Chen et al., 2014). Rats continuously treated with ginsenoside $\mathrm{Rg} 2$ at low $\left(2.5 \mathrm{mg} \mathrm{kg}^{-1}\right)$, medium $\left(5.0 \mathrm{mg} \mathrm{kg}^{-1}\right)$, or high doses $\left(10 \mathrm{mg} \mathrm{kg}^{-1}\right)$ for $3 \mathrm{~d}$ exhibited prolonged thrombosis time and a decrease in adenosine diphosphate (ADP)-induced platelet aggregation (Tian et al., 2009). Similarly, in a rat model of acute blood stasis in which three doses of $\mathrm{Rb}\left(25,50\right.$, and $\left.100 \mathrm{mg} \mathrm{kg}{ }^{-1}\right)$ were continuously administered for $7 \mathrm{~d}$, blood viscosity, platelet aggregation, and blood rheology were improved, which prevented high-viscosity conditions in the coronary artery during acute myocardial infarction, thrombosis formation, and the occurrence and development of AS (He et al., 2007). Rg1 has also been shown to inhibit platelet aggregation and activation induced by thrombin, ADP, collagen, and the thromboxane analog U46619, likely via suppression of the extracellular signal regulated kinase (ERK) signaling pathway. An inhibitory effect on thrombus formation in vivo has also been demonstrated (Zhou et al., 2014). Ginsenoside Rp1 was found to inhibit platelet activation and thrombosis induced by collagen, which may be related to vasodilator-stimulated phosphoprotein activation and inhibition of ERK2 and p38 mitogen-activated protein kinase pathways (Endale et al., 2012).

\section{Anti-arrhythmic effects}

Current anti-arrhythmia drugs have the side effect of aggravating arrhythmias, prompting researchers to seek out alternative agents from herbal medicine. Ginsenosides can block ion channels, suggesting that they can be used to modulate arrhythmia (Wang et al., 2004). Three types of $\mathrm{Ca}^{2+}$ channel exist on the myocardial cell membrane: $\mathrm{B}$ background channels, and L- and T-type voltage-dependent channels. The L-type channel is the main conduit of intracellular $\mathrm{Ca}^{2+}$ during cell excitation.

Ginsenoside $\mathrm{Rb} 1$ treatment was found to block $\mathrm{Ca}^{2+}$ currents in a dose-dependent manner at concentrations of $100-400 \mathrm{~mol} \mathrm{~L}^{-1}$ in cardiomyocytes isolated from reverse-perfused guinea pig hearts using a whole-cell voltage clamp technique (Zeng et al., 1997). In another study using isolated rat ventricular myocytes perfused with $\mathrm{Rb} 1$ (40 $\mu \mathrm{mol} \mathrm{L}{ }^{-1}$ ), L-type $\mathrm{Ca}^{2+}$ currents and transient outward $\mathrm{K}^{+}$currents were reduced without any alteration in channel kinetics (Pei et al., 2011). Ginsenoside Re administered at three doses (i.e., 5, 10, or $20 \mathrm{mg} \mathrm{kg}^{-1}$ ) converted a triggered ventricular arrhythmia into a normal sinus rhythm in a rabbit isoproterenol-induced arrhythmia model, an effect that was dose-dependent. The effects of ginsenoside on hemodynamics are negatively related to dosage (Chen et al., 2009); ginseng stem leaf saponins had dose-dependent antagonistic effects on chloroform-induced mouse ventricular cardiac arrhythmia and prevented aconitine-induced ventricular arrhythmia. Chloroform improved myocardial cell self-regulation linked to $\mathrm{Ca}^{2+}$ influx (Tang et al., 2009). Ginseng stem leaf saponins were also found to suppress aconitine-induced rat ventricular cardiac arrhythmia, possibly by modulating $\mathrm{Na}^{+}$channel function (Xiao et al., 2013). Ginsenoside Re (10 or $100 \mathrm{~mol} \mathrm{~L}^{-1}$ ) has been shown to exert anti-arrhythmic effects by inhibiting currents from ventricular voltage-dependent $\mathrm{Na}^{+}$, transient outward $\mathrm{K}^{+}$, and inward rectifier $\mathrm{K}^{+}$channels (Meng et al., 2013). In mice with toad venom-induced arrhythmia, $40 \mathrm{mg} \mathrm{kg}^{-1}$ total ginsenoside administration reduced the width of the QRS complex and increased T-wave amplitude, thereby diminishing the arrhythmia and prolonging survival (Lu et al., 2012).

\section{Protective effects of ginsenosides against myocardial ischemia}

In a Langendorff isolated heart model of ischemiareperfusion, 40-160 $\mathrm{mg} \mathrm{L}^{-1}$ ginsenoside pre-treatment and 
$80 \mathrm{mg} \mathrm{L}{ }^{-1}$ post-treatment had a protective effect against myocardial ischemia-reperfusion injury in rats, with greater effects observed with $80 \mathrm{mg} \mathrm{L}^{-1}$ pre- and post-treatment doses ( $\mathrm{Li}$ et al., 2005). Administration of total ginsenoside also improved myocardial ischemia-reperfusion coronary flow in a dose-dependent manner, which was likely associated with activation of the phosphoinositide 3-kinase/Aktendothelial (e) NOS pathway and increased NO release (Yi et al., 2010). In addition, ischemic ventricular myocyte $\mathrm{Ca}^{2+}$ ion channels and $\mathrm{Ca}^{2+}$ currents were inhibited in a dosedependent manner by Rb1 (100-400 $\mu$ mol L ${ }^{-1}$ ) (Zhang et al., 2007). Application of various doses of $\mathrm{Rb} 1$ in a $\mathrm{H}_{2} \mathrm{O}_{2^{-}}$ induced myocardial injury model had an anti-apoptotic effect via inhibition of lipid peroxidation and suppression of intracellular $\mathrm{Ca}^{2+}$ overload (Xu et al., 2005) and reactive oxygen species (ROS) production, which reduced oxidative damage and preserved mitochondrial function (Wen et al., 2010). Rb1 was also found to inhibit ROS-induced c-Jun N-terminal kinase (JNK) activation (Li et al., 2012) and ERK signaling (Yang et al., 2014). Re and Rg1 had protective effects on ${ }^{60} \mathrm{Co}$ irradiation-induced cardiomyocyte apoptosis that were exerted via attenuation of caspase 3 and $\mathrm{B}$ cell lymphoma (Bcl)-2-associated X protein (bax) expression and JNK/p38 signaling (Wu and Liu, 2008).

Administration of various doses of $\operatorname{Rg} 1$ promoted the formation of coronary artery collaterals in a rat acute myocardial infarction model, which may be associated with the upregulation of vascular endothelial growth factor expression and stimulation of angiogenesis (Zhang et al., 2009, 2013; Jin et al., 2007). In a rat coronary artery ligation-induced ischemia-reperfusion model, Rb1 (4 $\mathrm{mg} \mathrm{kg}^{-1}$ ) suppressed myocardial cell apoptosis (Zhang et al., 2001). Ginsenoside $\operatorname{Rg} 3$ (60 $\mathrm{mg} \mathrm{kg}^{-1}$ ) was also shown to have a protective effect on the myocardium via Akt/eNOS signaling and modulation of the $\mathrm{Bcl}-2 / \mathrm{Bax}$ ratio (Wang et al., 2015). In the same model, $\operatorname{Rg} 1\left(1-4 \mathrm{mg} \mathrm{kg}^{-1}\right)$ administered to guinea pigs in which acute myocardial ischemia was induced by pituitrin showed significant improvement in electrocardiogram readings as well as increased antioxidant enzyme activity, decreased oxidative damage from endothelial cell free radicals, and a reduction in myocardial cell membrane damage (Lai et al., 2011). Study in rats has shown that the effective dose of Re for protecting against heart ischemia-reperfusion injury in rats (determined by monitoring hemodynamic parameters such as perfusion pressure, aortic and coronary flow, cardiac output volume, and left ventricular pressure) was $100 \mu \mathrm{mol} \mathrm{L}{ }^{-1}$ (Kyuhee, et al., 2013). Pretreatment of diabetic rats with Rb1 (40 $\mathrm{mg} \mathrm{kg}^{-1}$ for $10 \mathrm{~min}$ ) reduced the severity of myocardial ischemia-reperfusion injury, which was associated with increased NOS expression and NO release and suppression of the oxidative stress response (Xia et al., 2011).

\section{Inhibition of ventricular remodeling}

Ventricular remodeling refers to an increase in myocardial injury or ventricle load following alterations in cell size or shape, or ventricular wall thickness and structure. This phenomenon is generally associated with lesion repair and ventricular compensation, and is a secondary pathophysiological reaction to myocardial infarction. Ventricular remodeling can lead to deterioration of left ventricular systolic function, followed by congestive heart failure and death. Recent evidence suggests that ginsenoside is effective in mitigating this process.

In a rat model of pressure overload-induced left ventricular remodeling, continuous administration of $\mathrm{Rb}$ at 25-100 mg kg-1 $\mathrm{d}^{-1}$ for six weeks by gavage had a protective effect against ventricular remodeling, with improved left ventricular systolic and diastolic functions, enhanced antioxidant enzyme activity, reduced myocardial damage by free radicals and vasoconstrictors, and a restoration of plasma prostacyclin prime/thromboxane $\mathrm{A}_{2}$ ratio (Wang et al., 2008). Left ventricular remodeling was reduced in rats with acute myocardial infarction by injection of $\mathrm{Rb} 1$ $\left(2 \mathrm{mg} \mathrm{kg}^{-1}\right)$ for four weeks, which was likely associated with negative regulation of the renin-angiotensin system (Wang et al., 2006). In neonatal rat cardiac myocytes in which hypertrophy was induced by angiotensin II, Rb1

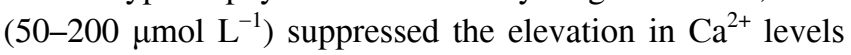
in a dose-dependent manner (Chen et al., 2008). Continuous application of $\mathrm{Rb} 1$ in a rat model of doxorubicin-induced heart failure reduced myocardial damage via modulation of connexin 43 , which may be associated with the regulation of p21-activated kinase 1/protein phosphatase 2A (Kong et al., 2013) and protein kinase RNA-like endoplasmic reticulum kinase signaling (Kong et al., 2013). Furthermore, $\mathrm{Rb} 1$ ( $70 \mathrm{mg} \mathrm{kg}^{-1} \mathrm{~d}^{-1}$ ) used as preventive therapy for 7 months in cTnTR $141 \mathrm{~W}$ mice with dilated cardiomyopathy resulted in an improvement in cardiac function and mitigated ultrastructural damage to heart tissue by reversing the disordered arrangement of myocardial cells (Zhao et al., 2009). Continuous application of $\operatorname{Rg} 1\left(5 \mathrm{mg} \mathrm{kg}^{-1} \mathrm{~d}^{-1}\right)$ in rats with acute myocardial infarction increased the number of peripheral blood stem cells, stimulated stem cell homing to the infarcted myocardium, and induced myocardial regeneration, thereby reducing infarct size and ventricular remodeling (Yang et al., 2008). Rb1 was also shown to inhibit colchicine-induced right ventricular hypertrophy, which may be associated with suppression of calcineurin signaling (Jiang et al., 2007).

\section{Other beneficial effects of ginsenosides}

In addition to the effects described above, ginsenosides have demonstrated protective effects against cardiac toxicity during cardiac surgery. In one study in which ginsenoside $\mathrm{Rd}\left(30 \mathrm{mg} \mathrm{kg}^{-1}\right)$ followed by bupivacaine $\left(2 \mathrm{mg} \mathrm{kg}^{-1} \mathrm{~min}^{-1}\right)$ was injected into rats for $30 \mathrm{~min}$, a significant improvement 
in blood oxygen level and saturation was observed, suggesting that ginsenoside pretreatment can increase survival rate in cases of cardiac toxicity caused by local anesthetics (Sun et al., 2010). A ginsenoside mixture (1.35 $\mathrm{mg} \mathrm{kg}^{-1}$ ) was reported to reduce gastrointestinal mucosal injury and inflammation caused by treatment of congenital heart disease in children (Xia et al., 2005). In addition, in vitro study has shown that the toxicity of aconitum to myocardial cells can be mitigated by co-administration with ginseng at a ratio of 1:0.5 (Wang et al., 2015). Another study reported that $\mathrm{Rg} 3$ protects vascular endothelial cells via a mechanism involving estrogen receptor that is similar to the effects of 17- $\beta$-estradiol (Pan et al., 2014).

\section{CONCLUDING REMARKS AND FUTURE PERSPECTIVES}

Studies of the mechanisms of cardiovascular protection by ginseng have mostly focused on the action of ginsenosides (Figure 2), and there are a variety of patented Chinese medicines (ginseng preparations) that are used to treat cardiovascular diseases (Table 2). The pharmacological effects of other ginseng components are rarely addressed (Im and Nah, 2013). Ginseng holds great promise for the treatment of cardiovascular diseases, with many potential applications. Based on its cardiovascular pharmacological effects, clinicians should pay close attention to the combinations of drugs that are used with ginseng. There are reports of co-injecting ShenFu (a ginsenoside compound) with statins to treat non-ischemic heart failure (Zheng et al., 2010), dopamine to reduce recovery time of in cases of shock (Xu and $\mathrm{Xu}, 2012$ ), metoprolol to treat coronary heart disease and heart failure (Yang and Lin, 2011), and trimetazidine to treat dilated cardiomyopathic heart failure (Yu et al., 2013). However, large, randomized, controlled, double blind clinical trials are needed to verify the clinical efficacy of these combinations, in addition to a more detailed analysis of the mechanisms of action. Despite the large number of products made from ginseng extract, there are no strict monitoring standards for their production, use, and quality control. The main method for extracting ginseng uses ethanol, followed by concentration and drying. However, due to the variety of purification methods adopted by different manufacturers,

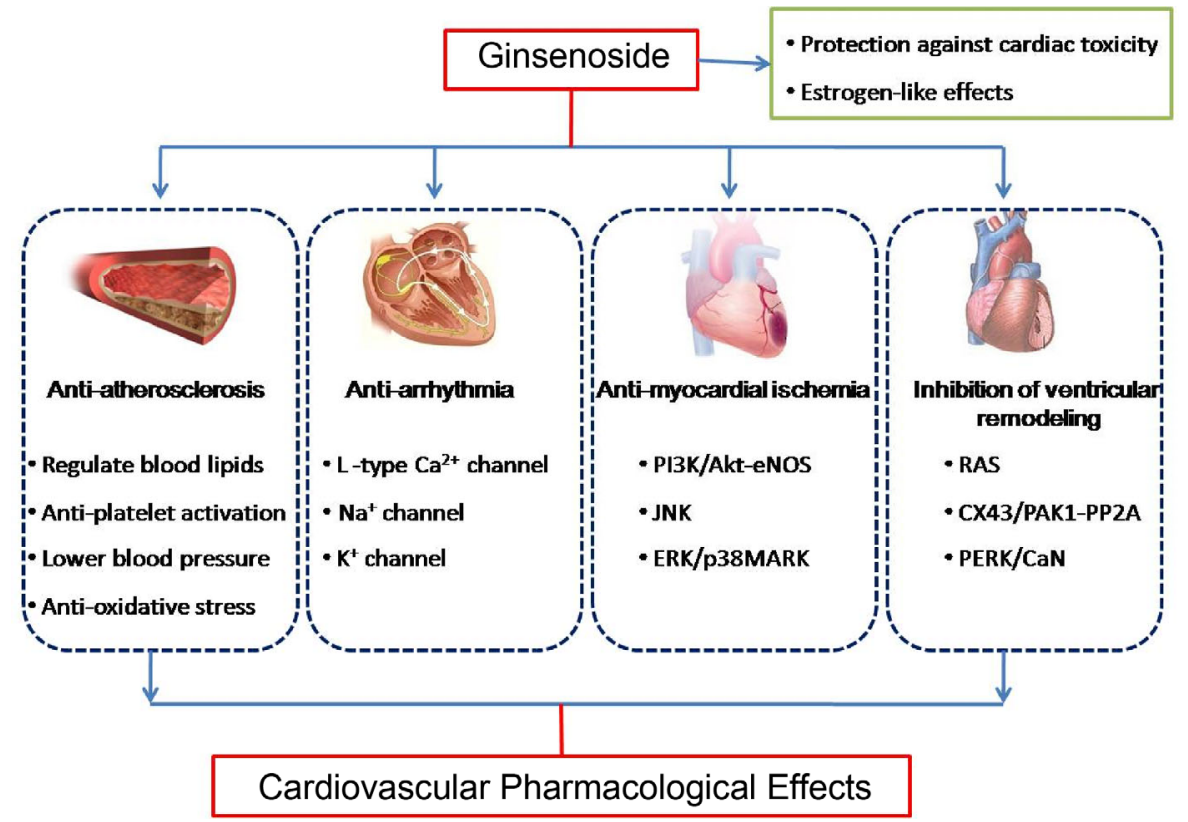

Figure 2 Putative mechanisms underlying cardiovascular protective effects of ginsenosides.

Table 2 Ingredients of frequently used patented Chinese medicines (ginseng preparations) for cardiovascular diseases

\begin{tabular}{|c|c|c|c|c|}
\hline No. & $\begin{array}{l}\text { Trade names of ginseng } \\
\text { preparations }\end{array}$ & Ingredients & Types of ginsenoside & References \\
\hline 1 & Zhenyuan capsule & $\begin{array}{l}\text { Total saponins in the fruit of Panax ginseng } \\
\text { C. A. Meyer }\end{array}$ & Ginsenoside $\operatorname{Re}$ & (Zhao, 2014) \\
\hline 2 & Xinyue capsule & Panax quinquefolium saponin & Ginsenoside $\operatorname{Rg} 1, \operatorname{Re}$, and Rb3 & (Yang et al., 2013) \\
\hline 3 & Shenmai injection & Red ginseng and Radix ophiopogonis & Ginsenoside $\operatorname{Rg} 1$ and $\operatorname{Re}$ & (Cao et al., 2011) \\
\hline 4 & Shengmai injection & $\begin{array}{l}\text { Red ginseng, Radix ophiopogonis, and } \\
\text { Schisandra chinensis }\end{array}$ & Ginsenoside Rb1 and Rc & (Lu et al., 2011) \\
\hline 5 & Shenfu injection & Red ginseng and Aconitum carmichaelii & $\begin{array}{l}\text { Ginsenoside Rd, Rb1, Rb2, Rc, } \\
\text { Rg1, and Ro }\end{array}$ & (He et al., 2014) \\
\hline
\end{tabular}


ginseng extracts differ significantly in terms of their properties, active ingredient content, and efficacy. Hence, to fully exploit the medicinal properties of ginseng and its extracts in the treatment of vascular diseases, production and monitoring systems must be improved. On the other hand, research on the possible toxicity of ginseng cannot be excluded; some studies have reported that Rb1 causes abnormalities in rat embryos (Chan, et al., 2003), which have aroused interest in exploring potential adverse effects of ginseng on development (Liu et al., 2005). Therefore, future research should not be confined to the benefits of ginseng and its preparations, and should be extended to a clarification of their mechanisms. With ongoing research on this versatile compound, more effective products will undoubtedly be developed for much-needed prevention and treatment of cardiovascular diseases.

Compliance and ethics The author(s) declare that they have no conflict of interest.

Acknowledgements This work was supported by the National Natural Science Foundation of China (81403266) and the Sponsored Project from Advisor of Beijing Outstanding Doctorate Dissertation (20138450201).

An, G., Ren, G., An, F., and Zhang, C. (2014). Role of C5a-C5aR axis in the development of atherosclerosis. Sci China Life Sci 57, 790-794.

Bai, M., Mao, Q., Xu, J., Zhu, L., Zhu, H., Wang, Q., and Li, S. (2014). Advance in saponins of aerial parts of Panax species (in Chinese). Chin J Chin Mater Med 39, 412-422.

Cao, S., Nie, L., Wang, G., and Lin, R. (2011). HPLC simultaneous determination of nine ginsenosides in Shenmai injection (in Chinese). J Pharm Anal 31, 476-478.

Chan, L.Y., Chiu, P.Y., and Lau, T.K. (2003). An in-vitro study of ginsenoside Rb1-induced teratogenicity using a whole rat embryo culture model. Hum Reprod 18, 2166-2168.

Chen, C., and Zhang, H. (2009). Effect of ginsenoside Re on triggering ventricular arrhythmia in rabbits (in Chinese). J Prac Med 25, 2237-2240.

Chen, M., Shi, G., Huang, Z., Li, Y., Sun, H., and Li, W. (2014). Phamacological effects of ginsenoside Rb1 on balance of Th17/Treg cell in spontaneously hypertension rats (in Chinese). Guangming J Chin Med 29, 2534-2538.

Chen, X., Huang, X., and Wu, Q. (2008). Ginsenoside Rb1 inhabits cardiomyocyte hypertrophy induced by angiotensin II (in Chinese). J Zunyi Med Univ 31, 457-460.

Chu, S., and Zhang, J. (2009). New achievements in ginseng research and its future prospects. Chin J Integr Med 15, 403-408.

Endale, M., Lee, W.M., Kamruzzaman, S.M., Kim, S.D., Park, J.Y., Park, M.H., Park, T.Y., Park, H.J., Cho, J.Y., and Rhee, M.H. (2012). Ginsenoside-Rp1 inhibits platelet activation and thrombus formation via impaired glycoprotein VI signaling pathway, tyrosine phosphorylation and MAPK activation. Br J Pharmacol 167, 109-127.

Gao, Y., Wu, Q., Yang, D., Deng, J., and Huang, X. (2012). Inhibitory effect of ginsenoside $\operatorname{Rg} 1$ on vascular neointimalhyperplasiainduced by balloon-injury in rats and the relation to its anti-oxidantaction and up-regulating of eNOS expression (in Chinese). Chin Pharmacol Bull, 28, 388-392.

Hao, P., Jiang. F., Chen, Y., Yang, J., Zhang, K., Zhang, M., Zhang, C., Zhao, Y., and Zhang, Y. (2015). Traditional Chinese medication for cardiovascular disease. Nat Rev Cardiol 12, 115-122.

He, F., Guo, R., Wu, S., Sun, M., and Li, M. (2007). Protective effects of ginsenoside $\mathrm{Rb} 1$ on human umbilical vein endothelial cells in vitro. $\mathrm{J}$
Cardiovasc Pharmacol 50, 314-320.

He, J., Zhou, S., Ma, Z., Liang, Q., Wang, Y., Tan. H., Xiao, C., Tang, X., and GAO, Y. (2014). Material basis of Shenfu injection based on UPLC-Q-TOF/MS (in Chinese). Chin Pharmacol Bull 30, 429-433.

He, X., Xu, H., Yu, X., Qu, S., and Sui, D. (2007). Effects of Ginsenoside- $\mathrm{Rb}$ on platelet aggregation and hemorheology in rats of acute blood stasis model (in Chinese). Chin Pharmacol Bull 23, 1259-1260.

Im, D.S., and Nah, S.Y. (2013). Yin and Yang of ginseng pharmacology: ginsenosides vs gintonin. Acta Pharmacol Sin 34, 1367-1373.

Jiang, Q., Huang, X., Dai, Z., Yang, G., Zhou, Q., Shi, J., and Wu, Q. (2007). Inhibitory effect of ginsenoside Rb1 on cardiac hypertrophy induced by monocrotalinein rat. J Ethnopharmacol 111, 567-572.

Jin, Y., and Liu, G. (2007). Effects of ginsenoside Rg1 on angiogenesis and VEGF expression in rats with acute myocardial infarction (in Chinese). J Chin Med Univ 36, 517-519.

Kim, Y.J., Zhang, D., and Yang, D.C. (2015). Biosynthesis and biotechnological production of ginsenosides. Biotechnol Adv 33, 717-735.

Kong, F., Sun, X., Zhao, X., and Li, Y. (2010). Experimental studies anti-atherosclerotic effects and mechanisms of ginsenoside Rh2 (in Chinese). J Beihua Univ (Nat Sci) 11, 520-523.

Kong, H., Hou, A., Guo, C., and Wang, J. (2013). Influence of ginsenosides $\mathrm{Rb} 1$ on adriamycin-induced heart failure by adjusting the protein kinase R-like ER kinase pathway (in Chinese). Chin J Histoch Sytoch 22, 290-295.

Kong, H., Li, Z., Miao, Z., and Ye, L. (2013). Effects of ginesenosides-Rb1 on connexin 43 in heart failure in rats (in Chinese). Tianjin Med J 41, $675-678$.

KyuHee, L., Dae-Jun, L., and Jong-Hoon, K. (2013). Ginsenoside-Re ameliorates ischemia and reperfusion injury in the heart: a hemodynamics approach. J Ginseng Res 37, 283-292.

Lai, F., Pan, Y., Ai, X., Jia, L., Zhu, K., Yang, Y., and Chen, M. (2011). Protective effect of ginsenoside $\mathrm{Rg} 1$ on acute myocardial ischemia in guinea pigs (in Chinese). Tradit Chin Drug Res Clin Pharmacol 22, 390-393.

Li, J., Shao, Z., Xie, J., Wang, C., Ramachandran, S., Yin, J., Aung, H., Li, C., Qin, G., VandenHoek, T. and Yuan, C. (2012). The effects of ginsenoside Rb1 on JNK in oxidative injury in cardiomyocytes. Arch Pharm Res 35, 1259-1267.

Li, J., Zhu, S., and Zeng, Y. (2005). Protective effects of different concentrations of ginsenoside on isolated heart ischemia reperfusion injury in rats (in Chinese). Chin J Anesth 25, 618-620.

Liu, P., Xu, Y., Yin, H., Zhang, Z., Wang, J., Chen, K., and Li, Y. (2005). Effects of ginsenoside Rb1 on mouse embryonic development in vitro (in Chinese). J Hygiene Res 34, 175-177.

Lu, J., Li, X., Wei, W., Yang, R., Zhang, P., Yao, H., and Jin, Y. (2011). RP-HPLC determination of seven ginsenosides in Shenmai injection (in Chinese). J Pharm Anal 31, 2302-2304.

Lu, W., Zhou, J., Ma, H., Lv, G., You, F., and Ding, A. (2012). Effects of astragaloside IV, ginsenoside and total saponins of panaxquinquefolium on mice with arrhythmia caused by toad venom (in Chinese). J Nanjing Univ Tradit Chin Med 28, 61-64.

Meng, H., Yao, M., and Liu, J. (2013). Effects of ginsenoside Re on sodium and potassium current in rat ventricular myocytes (in Chinese). World Chin Med 8, 1147-1149.

Pan, Y., Guo, C., Ma, X., Wang, J., Liu, X., Sun, M., Zhang, M., and Yin, H. (2014). The estrogen-like protective effect of ginsenoside Rb3 on oxidative stress and dysfunction of endothelial cells induced by oxidized low-density lipoprotein (in Chinese). Acta Pharma Sin 49, 1406-1412.

Pei, J., Zhang, Y., Chen, J., Huang, J., and Pu, J. (2011). Electrophysiological effect of ginsenoside Rb1 on L-type calcium current and transient outward potassium current in isolated rat ventricular myocytes (in Chinese). Mol Cardiol China 11, 230-234.

Ruan, Q., Song, J., and Deng, Z. (2004). Effects of ginsenosides on lipopolysaccharide-induced plasminogen activator inhibitor type-1 and NF-kappa B expression in vascular endothelial cells (in Chinese). Chin J Cardiol 32, 351-354.

Sun, L., Yang, S., Wang, Q., Zhu, X., and Xiong, L. (2010). Effect of 
ginsenoside $\mathrm{Rd}$ injection on the central and cardiac toxicity of bupivacaine in rats (in Chinese). Chin Heart J 22, 824-827.

Tang, Z., Tang, T., Fu, L., Tang, Y., Xiang, Y., Fan, H., and Lin, Y. (2009). Effects of ginseng stem leaf glucoside on mouse arrhythmia and death time (in Chinese). Lab Animal Sci 26, 4-7.

Tian, J., Song, L., Li, H., Ye, J., and Li, Y. (2009). Effects of thrombosis and platelet aggregation of ginsenosides $\operatorname{Rg} 2$ in rats (in Chinese). Shanghai J Tradit Chin Med 43, 79-80.

Wang, T., and Zhang, H. (2004). Review of anti-arrhythmic effects in Ginseng (in Chinese). Chin J Cardiac Pacing Electrophysiol 18, 309-310

Wang, T., Yu, X., Qu, S., Xu, H., Han, D., and Sui, D. (2008). Effects of Ginsenoside $\mathrm{Rb}$ on ventricular remodeling in rats with pressure overloaded hypertrophic myocardium and its mechanism (in Chinese). Lishizhen Med Mater Med Res 19, 1615-1617.

Wang, W., Zhao, L., Wang, L., Li, P., and Liu, Z. (2006). Effects of ginsenosid $\mathrm{Rb} 1$ on left ventricular remodeling after myocardial infarction in rats (in Chinese). J Chin Microcirc 10, 256-258.

Wang, X., Li, L., Li, Y., Li, C., and Zhang, D. (2015). Toxicity-reducing effect of compatibility of aconiti lateralis radix praeparata with different proportion of panax ginseng in neonatal Rat cardiomyocytes (in Chinese). Chin J Exp Tradit Med Form 21, 153-158.

Wang, Y., Hu, Z., Sun, B., Xu, J., Jiang, J., and Luo, M. (2015). Ginsenoside $\operatorname{Rg} 3$ attenuates myocardial ischemia/reperfusion injury via Akt/endothelial nitric oxide synthase signaling and the B-cell lymphoma/B-cell Lymphoma-associated X protein pathway. Mol Med Rep 11, 4518-4524.

Wen, F., Zhang, F., and Leng, Q. (2010). Protective effect of ginsenoside $\mathrm{Rb} 1$ on the apoptosis of cardiomyocytes induced by hydrogen peroxide (in Chinese). Hubei J Tradit Chin Med 32, 5-7.

Wu, J., and Liu, Y. (2008). Protective effect of ginsenoside Re on apoptosis of myocardial cells induced by ${ }^{60} \mathrm{Co}$ irradiation (in Chinese). Chin J Integr Med Cardio/Cerebro Dis 6, 923-924.

Xia, R., Zhao, B., Wu, Y., Hou, J., Zhang, L., Xu, J., and Xia, Z. (2011). Ginsenoside $\mathrm{Rb} 1$ preconditioning enhances enos expression and attenuates myocardial ischemia/reperfusion injury in diabetic rats (in Chinese). J Biomed Biotechnol 2011, 767930.

Xia, Z., Liu, X., Zhan, L., He, Y., Luo, T., and Xia, Z. (2005). Ginsenosides compound (shen-fu) attenuates gastrointestinal injury and inhibits inflammatory response after cardiopulmonary bypass in patients with congenital Heart disease (in Chinese). J Thorac Cardiovasc Surg 130, 258-264.

Xiao, Y., Ma, Z., Wang, Y., Tang, H., Zhao, Y., Liang, Q., Tang, X., Xiao, C., and Gao, Y. (2013). Study of Shenfu pracparata on the toxicity effects of antiarrhythmia induced by aconitine (in Chinese). Pharmacol Clin Chin Mater Med 29, 12-15.

Xu, H., Ge, Y., Deng, T., Wang, T., and Zheng, X. (2005). Protective effect of ginsenoside $\mathrm{Rb} 1$ against $\mathrm{H}_{2} \mathrm{O}_{2}$-induced apoptosis in neonatal rat cardiomyocytes (in Chinese). Chin Pharmacol Bull 21, 803-806.

$\mathrm{Xu}, \mathrm{W}$., and Xu, L. (2012). Clinical study on the treatment of septic shock in the combined treatment of the early stage of the treatment (in Chinese). J Emer in Tradit Chin Med 21, 1740-1741.

Yang, C., Ren, J., Wu, H., and Wang, Y. (2014). Protective effect of ginsenoside Rb1 on myocardial cell injury induced by ERK1/2 in rats induced by $\mathrm{H}_{2} \mathrm{O}_{2}$ (in Chinese). Chin J Integr Med Cardio/Cerebro Dis 12, 207-209.
Yang, M., Chen, G., Chen, C., Zhang, Y., and Yan, C. (2008). Effect of Ginsenoside $\operatorname{Rg} 1$ in promoting myocardial regeneration after myocardial infarction in rats (in Chinese). Chin Heart J 20, 697-707.

Yang, Q., and Lin, X. (2011). Clinical study on treatment of coronary heart failure with ShenFu injection and metoprolol (in Chinese). HeiLongJiang Med J 35, 114-115.

Yang, Y., Wang, H., and Yu, W. (2013). The determination of ginsenoside $\mathrm{Rg} 1$, ginsenoside Re and ginsenoside Rb3 in Xinyue capsules by HPLC (in Chinese). Modern Chin Med 15, 887-890.

Yao, J., Kong, W., and Jiang, J. (2015). Learning from berberine: treating chronic diseases through multiple targets. Sci China Life Sci 58, 854-859.

Yi, X., Li, T., Wang, J., Wong, V., Luo, P., Wong, I., Jiang, Z., Liu, L., and Zhou, H. (2010). Total ginsenosides increase coronary perfusion flow in isolated rat hearts through activation of PI3K/Akt-eNOS signaling. Phytomedicine 17, 1006-1015.

Yu, M., Lv, S., Liu, Z., and Fang, R. (2013). Observation of Shenfu injection combined with trimetazidine treatment of dilated cardiomyopathy heart failure (in Chinese). Chin J Tradit Med Sci and Tech 20, 642-643

Zeng, Q., Zhan, S., Zhang, W., Sun, X., and Zhong, G. (1997). Research on $\mathrm{ICa}^{2+}$ current inhibition effects of ginsenoside Rg1 in myocyte of guinea pig (in Chinese). J N Bethune Univ Med Sci 23, 265-267.

Zhang, J. (1995). The review and outlook of ginseng research (in Chinese). Yao Xue Xue Bao 30, 321-325.

Zhang, J. Chemistry, Biological Activity and Pharmacokinetics of Panax Ginseng Meyer, 2nd ed. (2012). Beijing: Chemical Industry Press.

Zhang, Q., Chen, Y., Liu F and Chen X. (2013). Ginsenoside-Rg1 promotes angiogenesis in rats with acute myocardial ischemia (in Chinese). J Thir Milit Med Univ 35, 42-45.

Zhang, Y., and Dong, E. (2014). New insight into vascular homeostasis and injury-reconstruction. Sci China Life Sci 57, 739-741.

Zhang, R., and Liu, Y. (2009). Effects of ginsenoside Rg1 on blood vessel regeneration and VEGF expression in rats with acute myocardial infarction (in Chinese). Chongqing Med 38, 805-807.

Zhang, W., Li, L., Zhao, C., Li, X., Zhao, M., and Zhong, G. (2007). Effects of panaxadiolsaponins monomer Rb1 on action potential and L-type calcium channel in ischemic cardiomyocytes (in Chinese). J Jilin Univ (Med Edition) 33, 978-981.

Zhang, W., Zhang, W., Li, Y., and Zhong, G. (2001).Effect of Rb1 on adult rat cardiomyocytes apoptosis (in Chinese). J N Bethune Unv Med Sci 27, 598-600.

Zhang, X., Qu, S., Sui, D., Yu, X., and Lv, Z. (2004). Effects of ginsenoside $\mathrm{Rb}$ on blood lipid metabolism and anti-oxidation in hyperlipidemia rats (in Chinese). Chin J Chin Mater Med 29, 1085-1088.

Zhao, H., Feng, J., Lv, D., Xiang, Z., Ma, C., Qin, C., and Zhang, L. (2009). Ginsenoside-Rb1 improved cardiac function and inhibited cardiac remodeling in transgenic mouse model of dilated cardiomyopathy (in Chinese). Chin J Compara Med 19, 6-10.

Zhao, Y. (2014). The content analysis method of ginsenoside-Re in Zhenyuan capsules (in Chinese). Chin J Pharma Econo 1, 41-42.

Zheng, G., Li, J., and Wang, J. (2010). Clinical study on the treatment of dilated cardiomyopathy heart failure with the combination of statins and ShenFu Injection (in Chinese). Chin J Tradit Med Sci Tech 17, $482-483$.

Zhou, Q., Jiang, L., Xu, C., Luo, D., Zeng, C., Liu, P., Yue, M., Liu, Y., $\mathrm{Hu}, \mathrm{X}$., and $\mathrm{Hu}, \mathrm{H}$. (2014). Ginsenoside $\mathrm{Rg} 1$ inhibits platelet activation and arterial thrombosis. Thromb Res 133, 57-65.

Open Access This article is distributed under the terms of the Creative Commons Attribution License which permits any use, distribution, and reproduction in any medium, provided the original author(s) and source are credited. 